\title{
STATUS STOK, EKSPLOITASI DAN OPSI PENGELOLAAN SUMBERDAYA IKAN TUNA DI LAUT BANDA
}

\section{STOCK STATUS, EXPLOITATION AND THE MANAGEMENT OPTION OF TUNA RESOURCES IN BANDA SEA}

\author{
Agustinus Anung Widodo', Ralph Thomas Mahulette ${ }^{1}$ dan Fayakun Satria ${ }^{2}$ \\ ${ }^{1}$ Pusat Penelitian Pengelolaan Perikanan dan Konservasi Sumber Daya Ikan \\ ${ }^{2}$ Balai Penelitian Pemulihan dan Konservasi Sumber Daya Ikan \\ Teregistrasi I tanggal: 05 September 2014; Diterima setelah perbaikan tanggal: 07 April 2015; \\ Disetujui terbit tanggal: 10 April 2015 \\ E-mail: anungwd@yahoo.co.id
}

\begin{abstract}
ABSTRAK
Laut Banda merupakan salah satu daerah penangkapan tuna yang potensial di Indonesia, Jenis alat tangkap yang digunakan terdiri dari pukat cincin, huhate, rawai tuna, pancing ulur dan pancing tonda. Hasil tangkapan tuna di Laut Banda meliputi cakalang, madidihang dan tuna mata besar. Sumberdaya tuna di Laut Banda diduga masih merupakan sub stok sumberdaya tuna di perairan Pasifik Tengah dan Barat. Hasil kajian stok tuna oleh Western and Central Pacific Fisheries Commission (WCPFC) pada 2012 melaporkan bahwa stok cakalang dan madidihang tidak mengalami overfishing dan overfished, sedangkan tuna mata besar telah mengalami overfishing dan overfished. Hasil penelitian Pusat Penelitian Pengelolaan Perikanan dan Konservasi Sumber Daya Ikan (P4KSI) pada 2012 menunjukkan madidihang dan tuna mata besar tertangkap pukat cincin, huhate serta kombinasi pancing ulur permukaan dan pancing tonda pada stadium yuwana, dengan indikasi nilai $\mathrm{L}_{c}<\mathrm{L}_{m}$. Jumlah yuwana madidihang dan tuna mata besar yang tertangkap pukat cincin masing-masing mencapai sekitar 7,9 ton (26\%) dan 1,5 ton (5\%) dari rerata total hasil tangkapan sekitar 30,29 ton/kapal/trip. Jumlah yuwana madidihang dan tuna mata besar yang tertangkap huhate sekitar 0,71 ton (15\%) dan 0,23 ton (5\%) dari rerata total tangkapan sekitar 4,79 ton/kapal/trip. Jumlah yuwana madidihang dan tuna mata besar yang tertangkap pancing ulurpancing tonda sekitar $17 \%$ dan $2 \%$ dari rerata total tangkapan sebesar 0,31 ton/kapal/trip. Saat ini hasil tangkapan tuna yang berasal dari pukat cincin tidak dikehendaki pasar ekspor, mereka lebih memilih tuna hasil tangkapan huhate ataupun jenis pancing lainnya. Oleh karena itu salah satu kebijakan pengelolaan perikanan tuna di Laut Banda adalah tidak mengembangkan alat tangkap pukat cincin, adapun huhate, pancing ulur-pancing tonda masih tetap dapat dioperasikan.
\end{abstract}

KATA KUNCI: Status stok, eksploitasi, opsi pengelolaan, tuna, Laut Banda

\begin{abstract}
ABTRACT
Banda sea is one of potential tuna fishing grounds among others in Indonesia. Various fishing gear types were operatedin this fishing ground such as pole \& line ( $P L)$, tuna long line (LL), hand line $(H L)$ and troll line (TR). Skipjack (SKJ), yellowfin tuna (YFT) and bigeye tuna (BET) are main species caught in Banda sea and currently assumed as one stock in the Western Central Pacific Ocean (WCPO). Recent stock assessment done by WCPFC in 2012 reported that BET is in overfishing state $\left(F>F_{m s y}\right)$ while YFT and $S K J$ are not in overfishing or overfished state. It was also reported by RCFMC that the size of catch of those species by various fishing gear indicating that value of $L_{c}<L_{m}$ or in other word that catches are in juvenile stage. The juvenile YFT and BET caught by purse seine were considerably high for $7.9 \mathrm{t}(26 \%)$ and $1.5 \mathrm{t}(5 \%)$ of the total catch 30.29 ton/ vessel/trip. YFT and BET caught by pole and line are only $0.71 \mathrm{t}(15 \%)$ and $0.23 \mathrm{t}(5 \%)$ of the total catch 4.79 ton/vessel/trip. YFT and BET caught by hand line and troll line were only $17 \%$ and $2 \%$ of total catch 0.31 ton/vessel/trip. Considering the high pressure of purse seine to juvenile of tuna resource and market preference, so that to the best fishing practice for resource sustainability it is suggestted for tuna management in Banda sea should be not to develop and increase the effort for purse seine and may shift to pole line, hand line and/or troll line are still openated.
\end{abstract}

KEYWORDS: Stock status, exploitation, management option, tuna, Banda Sea 


\section{PENDAHULUAN}

Perairan Laut Banda sebagai kesatuan ekosistem merupakan perpaduan dari tiga keistimewaan yaitu merupakan laut kontinen yang sempit, bersifat oseanik (laut dalam) dan terletak di daerah tropis (Nurhakim et al., 2007). Sacara oseanografis, Laut Banda merupakan bagian penting dari sistem dinamika arus lintas Indonesia (ARLINDO) atau Indonesian through flow, yang menghubungkan massa air dari Samudera Pasifik ke Samudera Hindia (Sulaiman, 2000). Turbulensi dan penaikan massa air (upwelling) di Laut Banda diyakini sebagai salah satu penyebab perairan ini kaya sumberdaya ikan (Nontji, 2007). Pada 2011 Laut Banda mampu memasok sekitar 536.992 ton ikan dan sekitar 96.908 ton (15,3\%) merupakan sumberdaya ikan tuna dengan rincian jumlah tersebut adalah cakalang atau SKJ (Katsuwonus pelamis) 66.852 ton (68,96\%), madidihang atau YFT (Thunnus albacares) 26.661 ton $(27,51 \%)$ dan tuna mata besar atau BET (Thunnus obesus) 3.396 (3,51\%) (DJPT, 2012). Jenis alat tangkap yang digunakan untuk menangkap tuna di perairan Laut Banda meliputi rawai tuna (tuna long lines), pukat cincin (purse seine), huhate (pole \& lines), pancing ulur (deep and surface hand lines), pancing tonda (trolling lines).

Dalam rangka melengkapi kebutuhan bahan kebijakan pengelolaan perikanan tuna di Laut Banda, maka disusun tulisan ini. Data dan informasi yang digunakan merupakan hasil program enumerator yang berlokasi di Kendari pada 2012dan kegiatan penelitian di Ambon, Maumere dan Benoa pada Mei dan Oktober 2012 (Gambar 1). Pemilihan lokasilokasi penelitian dikarenakan umumnya bahwa ikan tuna yang didaratkan di lokasi-lokasi tersebut merupakan hasil tangkapan berasal dari Laut Banda. Selanjutnya data dan informasi tersebut digunakan untuk updatinginformasi hasil penelitian Balai Penelitian Perikanan Laut(BPPL) dan Loka Penelitian Perikanan Tuna (LPPT) padakurun waktu 5 tahun terakhir. Informasi mengenai stok tunaberasal dari Western and Central Pacific Fisheries Commission (WCPFC) tahun 2012 dan Pusat Penelitian Pengelolaan Perikanan dan Konservasi Sumber Daya lkan (P4KSI tahun 2011.

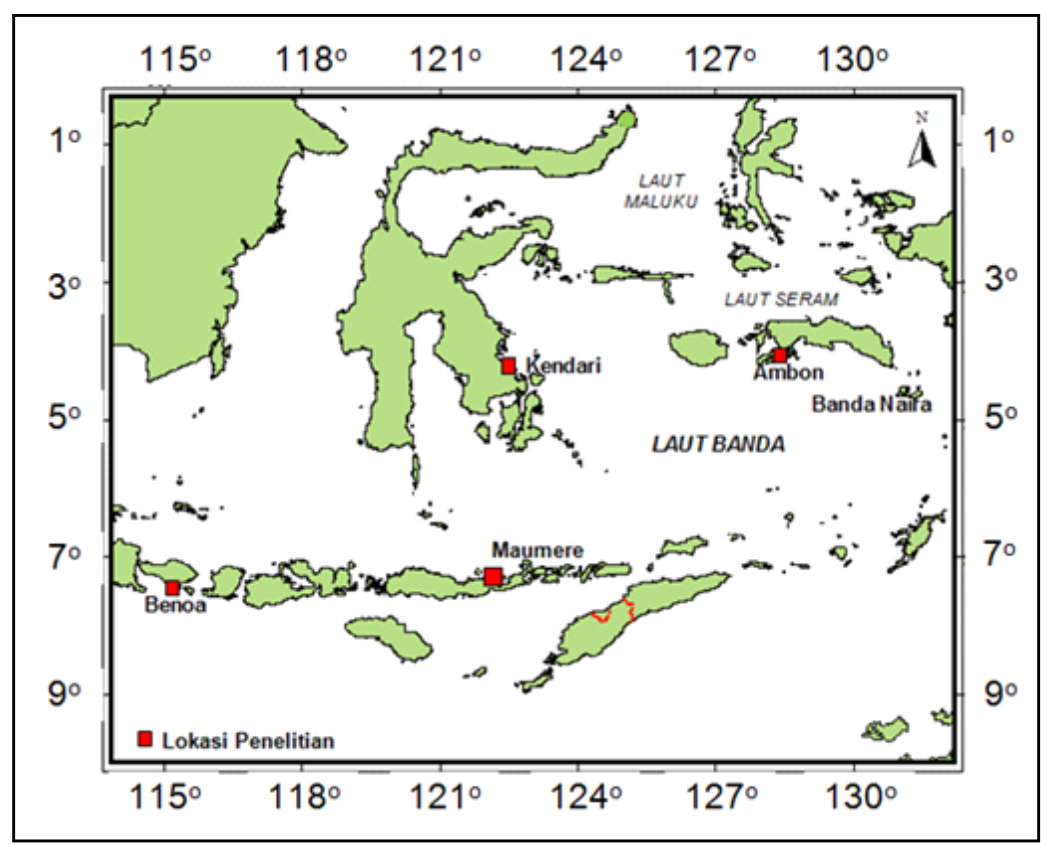

Gambar 1. Lokasi utama tempat pendaratan ikan tuna yang tertangkap di Laut Banda.

Figure 1. The main landing places of tuna caught in Banda Sea.

\section{STATUS STOK IKAN TUNA DI LAUT BANDA}

Tuna merupakan sumberdaya ikan peruaya jauh (Bayliff, 1984). Hasil penelitian melalui penandaan tuna (tuna tagging) kerjasama P4KSI dengan SPCWCPFC pada 2009-2010 menunjukkan terjadi ruaya dan pergerakan secara timbal-balik antara sumberdaya ikan tuna yang berada di perairan Laut Banda, Seram, Ambon, Papua dan dari luar wilayah Indonesia. Struktur stok-populasi tuna di perairan Laut
Banda belum diketahui, masih dalam taraf penelitian, maka untuk saat ini masih diasumsikan bahwa stok tuna di Laut Banda merupakan bagian dari stok tuna Samudera Pasifik. Berdasarkan asumsi tersebut, maka estimasi stok ikan tuna di perairan Laut Banda masih didasarkan pada estimasi regional. Perairan Laut Banda adalah bagian dari area statistik perikanan wilayah WCPFC, sehingga sumberdaya ikan tuna yang ada merupakan bagian stok sumberdaya tuna dari perairan Samudera Pasifik Bagian Barat. 
Hasil pengkajian stok tuna di area perairan WCPFC pada 2011 menunjukkan bahwa estimasi maximum sutainable yield (MSY) untuk sumberdaya cakalang (Katsuwonus pelamis) adalah 1.428.400 ton dengan estimasi jumlah tangkapan sekitar 1.124.000 ton, stok sumberdaya cakalang belum mengalami ovefished maupun overfishing (Davies et al., 2011) MSY untuk sumberdaya ikan madidihang (Thunnus albacares) berkisar antara 480.000-580.000 ton dengan estimasi jumlah tangkapan sekitar 550.000 ton (Langley et al., 2011), status stok madidihang 'belum mencapai tingkatoverfished'maupun 'overfishing'. Untuk tuna mata besar nilai MSY sekitar 74.993 ton, adapun estimasi jumlah tangkapan telah mencapai dua kali lipat dari nilai MSY-nya. Jika menggunakan skenario yang lebih optimistik sekalipun, yaitu dengan asumsi adanya penambahan rekruitmen maka estimasi besaran nilai MSY menjadi 131.400 ton, namun jumlah tangkapan mencapai $7 \%$ lebih tinggi dari estimasi nilai MSY tersebut (Holey et al., 2011). Dengan demikian stok sumberdaya tuna mata besar telah mengalami overfished dan overfishing.

Komposisi jenis tuna yang tertangkap di perairan Laut Banda berbeda menurutjenis alat tangkap yang dioperasikan oleh nelayan. Hasil pencatatan enumerator di pelabuhan Perikanan Samudera Kendari pada 2012 disajikan dalam Tabel 1.

Tabel 1. Komposisi jenis ikan tuna hasil tangkapan berdasarkan alat tangkap

Table 1. Catch composition of tuna based on gear types

\begin{tabular}{lccc}
\hline \multirow{2}{*}{ Alat Tangkap/Gear } & \multicolumn{3}{c}{ Komposisi jenis ikan hasil tangkapan /Catch composition (\%) } \\
\cline { 2 - 4 } & Cakalang (SKJ) & Madidihang (YFT) & $\begin{array}{c}\text { Tuna mata besar } \\
\text { (BET) }\end{array}$ \\
\hline Pukat cincin (PS) & 69 & 26 & 5 \\
Huhate (PL) & 77 & 15 & 8 \\
Pancing ulur (d-HL) & - & 55 & 45 \\
Pancing tonda (TR) & 81 & 17 & 2 \\
\hline
\end{tabular}

Kecuali pancing ulur dalam (d-HL), target utama pukat cincin, huhate dan pancing tonda adalah cakalang. Namun demikian tertangkap juga ikan madidihang dan tuna mata besar oleh pukat cincin, huhate maupun pancing tonda. Hal tersebut dapat dipahami karena pukat cincin, huhate dan pancing tonda dioperasikan di sekitar rumpon. Harley et al. (2010) dalam Morgan (2011). menyampaikan bahwa ikan-ikan yuwana tuna mata besar kerap berada di sekitar rumpon sehingga akan ikut tertangkap oleh pukat cincin.

Ukuran panjang cagak atau fork length (FL) tuna yang tertangkap di Laut Banda pada 2012 adalah sebagaimana disajikan dalam Tabel 2. Nilai ukuran panjang pertama kali tertangkap atau length of first captured $\left(\mathrm{L}_{c}\right)$ diperoleh melalui analisis, sedangkan ukuran panjang pertama kali dewasa atau length of first matured $\left(\mathrm{L}_{\mathrm{m}}\right)$ merupakan hasil penelitian sebelumnya yang dilakukan peneliti lain di perairan Samudera Pasifik (Tabel 3).

Berdasarkan informasi tersebut, maka madidihang dan tuna mata besar yang tertangkap PS, PL, s-HL dan TR merupakan tuna muda atau yuwana (juvenile) yang diindikasikan mempunyai ukuran $\mathrm{L}_{c}<\mathrm{L}_{\mathrm{m}}$. $\mathrm{k}$ kan madidihang yang tertangkap pancing ulur dalam (d$\mathrm{HL}$ ) yang dioperasikan di lapisan perairan dalam pada umumnya berukuran lebih besar yang mana ikan tersebut diperkirakan pernah mengalami pemijahan $\left(L_{c}>L_{m}\right)$. Apabila ikan tuna berukuran kecil (juvenile) banyak tertangkap dapat mengakibatkan 'growth overfishing'. Peristiwa ini dapat terjadi ketika kegiatan penangkapan ikan menyebabkan jumlah kehilangan (penurunan) biomasa suatu stok ikan lebih besar dibandingkan jumlah peningkatan biomasa karena pertumbuhan. Namun jika terjadi banyak tertangkap ikan dewasa yang siap memijah sehingga dapat menurunkan stok maka dapat memicu terjadinya 'recruitment overfishing'. Murawski (2000) menjelaskan bahwa 'recruitment overfishing'terjadi ketika biomasa ikan-ikan yang siap memijah (spawning biomass) dari suatu populasi ikan menurun, sehingga jumlah anakan untuk rekruitmen yang dihasilkan tidak cukup banyak untuk memulihkan populasi ikan tersebut. Keadaan menjadi lebih buruk jika ikan dewasa yang banyak tertangkap adalah ikan betina yang berukuran besar dan siap memijah. Ikan betina dewasa berukuran besar lebih banyak menghasilkan telur dibanding ikan betina dewasa ukuran lebih kecil. 
Tabel 2. Ukuran panjang cagak $(F L)$ dan pertama kali tertangkap $\left(\mathrm{L}_{c}\right)$ beberapa jenis ikan tuna berdasarkan jenis alat yang berbasis di Kendari pada 2012

Table 2. Fork length $(F L)$ and length of first captured $\left(L_{\partial}\right)$ of tunas based on gear based at Kendari in 2012

\begin{tabular}{|c|c|c|c|c|}
\hline $\begin{array}{c}\text { Basis } \\
\text { pendaratan/ } \\
\text { Landing Base }\end{array}$ & $\begin{array}{l}\text { Jenis alat } \\
\text { tangkap/ } \\
\text { Gear Type }\end{array}$ & $\begin{array}{c}\text { Jenis hasil } \\
\text { tangkapan/ } \\
\text { Species of Catch }\end{array}$ & $\begin{array}{l}\text { Kisaran FL/ } \\
\text { Range of FL } \\
\text { (cm) }\end{array}$ & $\begin{array}{l}\mathrm{L}_{\mathrm{c}}(\mathrm{cm}) / \\
\mathrm{L}_{\mathrm{c}}(\mathrm{cm})\end{array}$ \\
\hline PPS Kendari & Pukat cincin (PS) & Cakalang (SKJ) & 18-65 (md 43) & 43,5 \\
\hline \multirow[t]{2}{*}{ (Kendari) } & & Madidihang (YFT) & $20-69$ (md 42) & 42,8 \\
\hline & & $\begin{array}{l}\text { Tuna mata besar } \\
\text { (BET) }\end{array}$ & $24-63(\mathrm{md} \mathrm{45})$ & 46,4 \\
\hline PPS Kendari & Huhate (PL) & Cakalang (SKJ) & 24-68 (md 44) & 45,9 \\
\hline \multirow[t]{2}{*}{ (Kendari) } & & Madidihang (YFT) & 21-63 (md 41) & 41,8 \\
\hline & & Tuna mata besar (BET & - & - \\
\hline \multirow{3}{*}{$\begin{array}{l}\text { PPP Sodohoa } \\
\text { (Kendari) }\end{array}$} & Pancing ulur dalam & Cakalang (SKJ) & - & - \\
\hline & $(\mathrm{d}-\mathrm{HL})$ & Madidihang (YFT) & $106-153(m d 124)$ & 127,0 \\
\hline & & Tuna mata besar (BET & - & - \\
\hline \multirow{3}{*}{$\begin{array}{l}\text { PPP Sodohoa } \\
\text { (Kendari) }\end{array}$} & Pancing ulur & Cakalang (SKJ) & $18-65$ (md 43) & 44,6 \\
\hline & permukaan (s-HL) & Madidihang (YFT) & $25-67$ (md 42) & 45,1 \\
\hline & & Tuna mata besar (BET & - & - \\
\hline PPP Sodohoa & Pancing tonda (TR) & Cakalang (SKJ) & 24-62 (md 46) & 45,8 \\
\hline \multirow[t]{2}{*}{ (Kendari) } & & Madidihang (YFT) & 23-65 (md 43) & 43,8 \\
\hline & & Tuna mata besar (BET & - & - \\
\hline
\end{tabular}

Tabel 3. Ukuran panjang pertama kali dewasa atau length of first matured $\left(\mathrm{L}_{\mathrm{m}}\right)$ ikan cakalang, madidihang dan tuna mata besar hasil penelitian di perairan Samudera Pasifik

Table 3. Length of first matured $\left(L_{m}\right)$ of skipjack, yellowfin tuna and big eye tuna based on researched in Pacific waters

\begin{tabular}{|c|c|c|c|}
\hline Spesies/Species & $\begin{array}{l}\text { Ukuran Panjang/ } \\
\text { Length of } \\
\text { first matured } \\
L_{m}(\mathrm{~cm})\end{array}$ & Perairan/Waters & Sumber/Source \\
\hline $\begin{array}{l}\text { Cakalang - SKJ } \\
\text { (Katsuwonus pelamis) }\end{array}$ & $>42,5$ & - Perairan Selatan Jawa & $\begin{array}{l}\text { - Tampubolon et al. } \\
(2014)\end{array}$ \\
\hline $\begin{array}{l}\text { Madidihang-YFT } \\
\text { (Thunnus albacares) }\end{array}$ & $>50$ & - Perairan Hawaii & - Itano (2000). \\
\hline $\begin{array}{l}\text { Tuna mata besar-BET } \\
\text { (Thunnus obesus) }\end{array}$ & $>108$ & $\begin{array}{l}\text { - Perairan tropis } \\
\text { Pasifik } \\
\text { Timur dan Barat } \\
\text { ECTPO) }\end{array}$ & - Zhu et al. (2011) \\
\hline
\end{tabular}


Perairan Laut Banda yang terletak di daerah tropis dengan suhu hangat merupakan tempat ideal memijah bagi jenis ikan tuna. Hasil pengamatan gonada ikan tuna oleh BPPL pada 2007 dan 2011 memperkirakan bahwa cakalang memijah di perairan Laut Banda yang terjadi pada periode Juni-Juli dan madidihang sekitar Juni-September. Hasil penelitian BPPL pada 2011 menunjukkan bahwa perkiraan daerah asuhan (nursery ground) tuna di Laut Banda adalah di perairan selatan dan tenggara Bandanaira yaitu pada sekitar $4^{\circ} 32^{\prime} S-130^{\circ} 14^{\prime} \mathrm{T}$ dan $4^{\circ} 39^{\prime} \mathrm{S}-130^{\circ} 07^{\prime} \mathrm{T}$ serta selatan Haruku atau tenggara Ambon pada sekitar $3^{\circ} 39^{\prime} S$ $128^{\circ} 24^{\prime} \mathrm{T}$, yang diindikasikan oleh banyak tertangkapnya larva tuna. Pemijahan madidihang telah diteliti diantaranya, Schaefer (1988) dan pemijahan tuna mata besar telah diteliti Nikaido et al. (1991). Dari penelitian tersebut dapat ditarik kesimpulan madidihang dan tuna mata besar memilih memijah pada perairan hangat $>24^{\circ} \mathrm{C}$ dan tidak ada lokasi khusus (oportunistic) dan bersifat 'multispawner'. Diperairan Hawaii diketahui cakalang memijah sedikitnya 2 kali setahun yaitu akhir April atau awal Mei dan Juli atau awal Agustus.

\section{EKSPLOITASI}

Sumberdaya ikan tuna di Laut Banda dieksploitasi dengan menggunakan pukat cincin (purse seine), huhate (pole \& line), rawai tuna (tuna long lines), pancing ulur (hand lines) dan pancing tonda (troll lines). Pengoperasian pancing tonda biasanya dikombinasikan dengan pancing ulur, yaitu satu kapal penangkap ikan mengoperasikan dua jenis alat penangkapan ikan yang berbeda. Pancing ulur yang dioperasikan dibedakan menjadi dua, yaitu pancing ulur dalam atau deep hand line $(\mathrm{d}-\mathrm{HL})$ dan pancing ulur permukaan atau surface hand line (s-HL). Pancing ulur perairan dalam (d-HL) umumnya menggunakan mata pancing ukuran besar (No.7-8 Mustad) sehingga target utama adalah untuk menangkap ikan tuna khususnya madidihang berukuran besar yaitu berukuran FL antara 106-153 cm dengan modus 124 cm (Tabel 2). Sebaliknya pancing ulur permukaan (s$\mathrm{HL}$ ) menggunakan mata pancing berukuran kecil (<No.6 Mustad) sehingga ikan tuna khususnya madidihang berukuran kecil yaitu berukuran FL 25$67 \mathrm{~cm}$ dengan modus $42 \mathrm{~cm}$ (Tabel 2).

Selain rawai tuna, semua jenis alat penangkap ikan tuna tersebut di atas menggunakan alat bantu panangkapan berupa rumpon atau fish aggregating devices (FADs). Pukat cincin yang dioperasikan di sekitar FADs banyak menangkap ikan tuna muda, sedangkan pukat cincin yang dioperasikan di luar FADS/logs yaitu menangkap gerombolan ikan tuna yang bebas atau free schooling menghasilkan tuna dengan ukuran lebih besar (Romanov, 2002). Masalah rumpon pada perikanan tuna di Indonesia merupakan isu penting yang masih sulit penyelesaiannya. Rumpon yang dipasang oleh nelayan atau perusahaan penangkapan ikan tidak dilaporkan ke Kementerian Kelautan dan Perikanan sebagai otoritas terkait, sehingga jumlah maupun posisinyasulit diketahui. Hasil penelitian P4KSI pada 2012 di Laut Banda menunjukkan bahwa lebih dari 181 rumpon yang berhasil dicatat posisinya, menunjukkan bahwa ratarata jarak antar dua rumpon terdekat hanya berkisar antara 2,2-4,2 mil (Widodo et al., 2012). Sementara bukti ilmiah menunjukkan bahwa jarak terjauh agregasi tuna dari sebuah rumpon pada radius sekitar 5 mil pada siang hari dan 7 mil pada malam hari (Marsac \& Cayre, 1997). Oleh karena itu, sedikitnya jarak pemasangan antar rumpon seharusnya antara 10-14 mil. Peraturan Menteri Kelautan dan Perikanan Republik Indonesia Nomor 26/Permen-Kp/2014 Tentang Rumpon pada Pasal 12 butir 1d ditetapkan bahwa jarak minimum antar rumpon adalah 10 mil. Dengan demikian maka jarak pemasangan antar rumpon yang ada di Laut Banda saat ini menyalahi peraturan/Permen KP No.26 Tahun 2014 sehingga perlu ditertibkan.

Hasil tangkapan per upaya atau catch per unit effort (CPUE) sering digunakan untuk menggambarkan kemampuan alat tangkap untuk mengekploitasi sumberdaya ikan atau dapat juga digunakan sebagai indikator kelimpahan sumberdaya tersebut. CPUE pada perikanan huhate dan pukat cincin biasanya dinyatakan dalam laju tangkap (catch rate). Pada perikanan rawai tuna biasanya direpresentasikan sebagai laju pancing (hook rateHR). Pada pancing ulur maupun tonda belum ada kesepakatan, namun menurut (Griffiths et al., 2012) dapat menggunakan waktu lama memancing (jam) sebagai nilai upaya. Upaya pada CPUE alat penangkapan ikan tuna yang dioperasikan di perairan Laut Banda dengan basis pendaratan di Kendari disajikan sebagai kapal per trip (Tabel 4), meskipun metode ini agak kurang akurat dibanding metode penentuan CPUE seperti di atas.

Pukat cincin merupakan alat penangkapan ikan tuna paling produktif dibanding huhate dan tonda-pancing ulur. Pukat cincin menangkap tuna banyak (bulky) dengan kisaran ukuran ikan dari yang sangat kecil hingga besar, ukuran ikan (Tabel 2). 
Tabel 4. Estimasi Hasil tangkapan per upaya (CPUE) per jenis kapal di Kendari tahun 2012

Table 4. The estimate of catch per unit effort each vessel based at Kendari in 2012

\begin{tabular}{|c|c|c|c|c|c|c|}
\hline \multirow{2}{*}{$\begin{array}{l}\text { Alat } \\
\text { penangkap } \\
\text { ikan/Gear } \\
\text { type }\end{array}$} & \multirow{2}{*}{$\begin{array}{c}\text { Jumlah } \\
\text { trip/ } \\
\text { Trip } \\
\text { total }\end{array}$} & \multirow{2}{*}{$\begin{array}{c}\text { Total } \\
\text { Tangkapan } \\
\text { /Total catch } \\
\text { (ton)-[\%] }\end{array}$} & \multicolumn{3}{|c|}{$\begin{array}{c}\text { Komposisi jenis tangkapan/Catch } \\
\text { composition (ton)-[\%] }\end{array}$} & \multirow{2}{*}{$\begin{array}{c}\text { CPUE } \\
\text { (ton/kapal/trip) } \\
\text { (ton/boat/trip) }\end{array}$} \\
\hline & & & $\begin{array}{l}\text { Cakalang } \\
(\text { SKJ) }\end{array}$ & $\begin{array}{l}\text { Mdidihang } \\
\text { (YFT) }\end{array}$ & $\begin{array}{l}\text { Tuna mata } \\
\text { besar (BET) }\end{array}$ & \\
\hline Pukat & 168 & $(5.088)$ & $(3.511)$ & $(1.323)$ & (254) & 30,29 \\
\hline Cincin (PS) & & [100\%] & [69\%] & $(29 \%]$ & [5\%] & - \\
\hline \multirow[t]{2}{*}{ Huhate (PL) } & 492 & (2.357) & (1.579) & (588) & (190) & 4,79 \\
\hline & & [100\%] & [67\%] & [25\%] & [8\%] & - \\
\hline Pancing & 108 & (33) & $(23,4)$ & $(8,9)$ & $(0,7)$ & 0,31 \\
\hline Ulur (HL) & & [100\%] & {$[70,9 \%$} & {$[27,1 \%]$} & [2\%] & - \\
\hline
\end{tabular}

Data dan informasi laju pancing (hook rate) kapal rawai tuna adalah berdasarkan data yang dilaporkan Asosiasi Tuna Long Line Indonesia (ATLI) antara 20052010 bahwa laju pancing rawai tuna secara nasional mengalami penurunan nilai dari tahun ke tahun, termasuk di Laut Banda (Gambar 2). Khusus hook rate rawai tuna yang dioperasikan di Laut Banda belum diperoleh laporan yang detail.

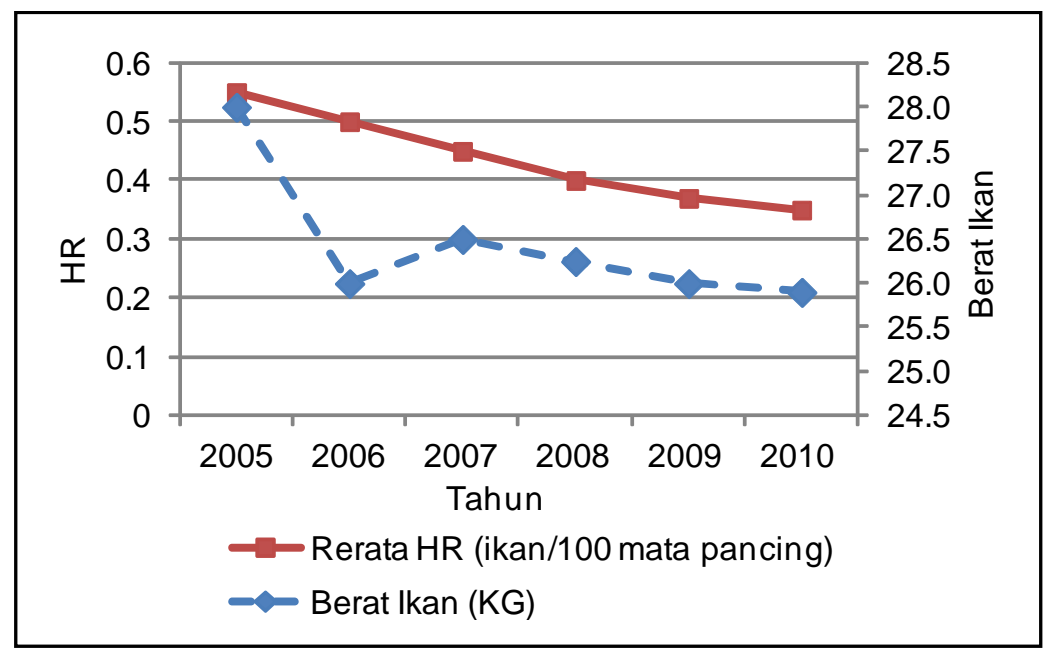

Gambar 2. Kecenderungan laju pancing dan ukuran tuna armada rawai tuna yang beroperasi di Laut Banda dengan berbasis di Benoa tahun 2005-2010.

Figure 2. Trend of hook rate and size of tuna caught by tuna long line in Banda sea based at Benoa in 2005-2010.

Sumber data/Data source: Asosiasi Tuna Longline Indonesia (ATLI) tahun 2010.

Hasil observasi WWF di Maumere-Nusa Tenggara Timur pada Mei 2012 diperoleh informasi adanya penangkapan ikan secara ilegal (illegal fishing) yaitu penangkapan ikan dengan menggunakan bom di sekitar Lembata. Lokasi terjadinya kegiatan penangkapan ikan tuna dengan bantuan bom adalah sebagaimana dipetakan pada Gambar 3.

Penyebab terjadinya kegiatan pengeboman sumberdaya tuna diduga dilatar belakangi beberapa faktor diantaranya: 1) minimnya penguasaan teknologi penangkapan yang benar, sedikitnya modal yang dimiliki nelayan, karena penggunaan bom dianggap mudah dan murah, 2) tidak memahami kerugian lingkungan yang diakibatkan karena kegiatan pengeboman, 3) pasar atau perusahaan pengolah ikan tuna tetap menerima tuna yang tertangkap dengan bantuan bom dengan harga tidak berbeda dari tuna hasil tangkapan API yang disarankan, 4) penegakan hukum yang kurang maksimal sehingga mengakibatkan kegiatan ini terus terjadi. 


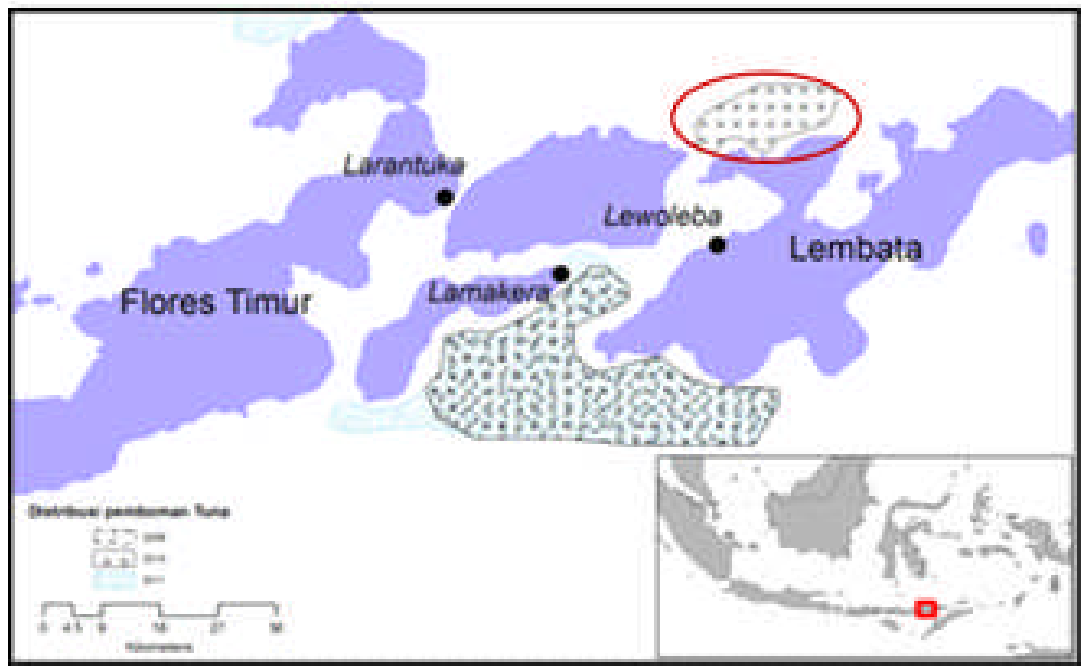

Gambar 3. Peta lokasi aktivitas pengeboman ikan tuna. Figure 3. Map of tuna fishing usingdynamite.

Sumber/Source: WWF (2011)

\section{OPSI PENGELOLAAN PERIKANAN}

Dengan mempertimbangkan kajian dan analisis informasi di atas, maka beberapa opsi pengelolaan perikanan tuna di perairan Laut Banda dapat disarankan seperti berikut:

(1) Pengembangan alat tangkap pukat cincin di Laut Banda dibatasi atau tidak dilakukan penambanhan armada, karena ikan tuna khususnya madidihang dan matabesar yang tertangkap pukat cincin merupakan ikan muda atau yuwana (juvenile).

(2) Rawai tuna dan pancing ulur (dalam dan permukaan), huhate dan pancing tonda tetap dapat dikembangkan di perairan Laut Banda. Hal tersebut didasari oleh kenyataan bahwa rawai tuna dan pancing ulur terbukti menangkap tuna madidihang dan mata besar dewasa dengan indikasi mempunyai $L_{c}>L_{m}$. Huhate mempunyai target tangkapan ikan cakalangdengan hasil tangkapan sampingan (by bacth) yuwana tuna madidihang dan mata besar namun persentase jumlah tangkapan kedua spesies tersebut cukup sedikit. Kombinasi alat tangkap pancing ulur permukaan dan pancing tonda juga yuwana tuna madidihang dan mata besar namun persentasenya juga sangat sedikit.Saat ini pasar internasional lebih memilih (menerima) tuna madidihang dan matabesar hasil tangkapan rawai tuna, huhate, pancing ulur dan pancing tonda dibandingkan dengan tuna hasil tangkapan pukat cincin. Pengembangan armada huhate membutuhkan umpan hidup terutama jenis ikan teri (Stolephorus spp.) yang selama ini disediakan oleh nelayan bagan. Didasari oleh informasi tentang nursery ground tuna di Laut Banda yang telah dapat dipetakan yaitu berada di selatan dan tenggara Bandanaira pada sekitar $4^{\circ} 32^{\prime} \mathrm{S}-130^{\circ} 14^{\prime} \mathrm{T}$ dan 4'39'S-13007'T serta selatan Haruku atau tenggara Ambon pada sekitar $3^{\circ} 39^{\prime} S-128^{\circ} 24^{\prime} T$. Direkomendasikan agar di nursery ground tuna tersebut tidak dilakukan pengoperasian bagan ataupun alat serupa karena alat penangkapan ikan tersebut tersebut efektif menangkap ikan-ikan kecil termasuk larva dan juwana tuna.

(3) Rumpon (FADs) digunakan sebagai alat bantu untuk mengumpulkan ikan tuna sebelum ditangkap dengan pukat cincin, huhate dan pancing ulur dioperasikan di Laut Banda. Pengoperasian alat tangkap ikan di perairan disekitar rumpon menyebabkan banyak tertangkapnya ikan tuna stadium yuwana (juvenile). Atraktan adalah bagian dari rumpon yang berfungsi untuk menarik ikan berkumpul, biasanya terbuat dari dedaunan jenis palma (termasuk daun kelapa) atau terbuat dari bahan sintetik sepeti jaring (webbing) bekas atau plastic. Terdapat beberapa resolusi yang dikeluarkan WCPFC sebagai contoh Conservation and management Measure (CMM) 2008-1 WCPFC tentang penutupan rumpon (FAD closure) dimana kapal pukat cincin tidak boleh melakukan operasi penangkapan dengan alat bantu rumpon pada area $20^{\circ} \mathrm{S}-20^{\circ} \mathrm{U}$ mulai 1 Agustus jam 00.00 hingga 30 September jam 24.00 setiap tahun. Dengan tindakan FAD closure memberi kesempatan sumberdaya tuna tumbuh menjadi besar yaitu dari ukuran yuwana (juvenile) menjadi ikan dewasa dan ikan dewasa memperoleh kesempatan melakukan 
pemijahan sehingga terjadi rekruitmen baru. Selama periode FADs closure, pukat cincin dapat melakukan penangkapan pada gerombolan ikan di luar rumpon (free schooling).

(4) Jumlah rumpon di Laut Banda tidak diketahui secara pasti, namun dari 181 rumpon yang dapat dicatat posisinya menunjukkan bahwa jarak antar rumpon terdekat umumnya $<4$ mil bahkan sebagian berjarak <1 mil. Peraturan Menteri Kelautan Dan Perikanan Republik Indonesia Nomor 26/Permen-Kp/2014 Tentang Rumpon, Bab 4, Pasal 12 (1) butir d bahwa jarak antara rumpon yang satu dengan rumpon yang lain tidak kurang dari 10 (sepuluh) mil, dan ayat e: pemasangan rumpon tidak boleh dengan jarak kurang dari 12 mil laut diukur dari garis pasang surut terendah pada waktu air surut dari setiap pulau; atau pada ayat f: rumpon tidak boleh dipasang dengan cara pemasangan yang mengakibatkan efek pagar (zigzag) yang dapat menutup jalur ruaya ikan.

\section{KESIMPULAN DAN SARAN}

Dari uraian tersebut di atas maka dapat disimpulkan seperti berikut:

(1) Stok sumberdaya tuna di Laut Banda diduga merupakan substok dari sumberdaya tuna di perairan Pasifik Tengah dan Barat sehingga status stoknya mengacu pada hasil kajian yang dilakukan WCPFC pada 2012 bahwa stok sumberdaya cakalang tidak mengalami overfished maupun overfishing, madidihang juga 'tidak mengalami overfished' maupun 'overfishing'. Tuna matabesar telah mengalami overfished maupun overfishing.

(2) Sumberdaya tuna madidihang dan tuna matabesar diekpolitasi menggunakan pancing ulur dalam dan rawai tuna. Pukat cincin banyak menangkap yuwana ikan tuna madidihang dan tuna matabesar sebagai by catch sehingga dapat mengakibatkan growth overfishing kedua jenis ikan tuna tersebut. Oleh karena itu agar pukat cincin dikurangi atau tidak dikembangkan atau status 'guo' di Laut Banda. Huhate dan kombinasi pancing ulur permukaan-tonda juga menghasilkan by catch yuwana tuna madidihang dan tuna mata besar, namun jumlahnya sedikit. Sedangkan rawai tuna dan pancing ulur dalam khusus menangkap madidihang dan tuna mata besar ukuran besar (dewasa). Dengan demikian huhate, rawai tuna, pancing ulur (dalam dan permukaan) serta pancing tonda tetap dapat dioperasikan di Laut Banda.

(3) Pengoperasian huhate membutuhkan dukungan pengoperasian alat tangkap ikan lain yaitu bagan untuk menangkap umpan hidup (ikan teri dan ikan kecil lainnya) yang sangat dibutuhkan pada pengoperasian huhate. Selain menangkap ikan umpan hidup, bagan juga potensial menangkap juwana dan larva ikan termasuk larva ikan tuna. Terindikasi bahwa larva tuna banyak ditemukan di Laut Banda pada lokasi selatan dan tenggara Bandanaira pada sekitar $4^{\circ} 32^{\prime}$ S- $130^{\circ} 14^{\prime} T$ dan 4'39'S-13007'T serta selatan Haruku atau tenggara Ambon pada sekitar $3^{\circ} 39^{\prime} \mathrm{S}-128^{\circ} 24^{\prime} \mathrm{T}$, oleh karena itu agar di perairan tersebut tidak dilakukan penangkapan ikan dengan alat tangkap ikan bagan.

(4) Rumpon (FADs) merupakan alat bantu pengumpul ikan pada pukat cincin, huhate, pancing ulur dan pancing tonda. Di Laut Banda diperoleh informasi posisi (lintang-bujur) sekitar 181 rumpon dengan jarak antar rumpon < 4 mil, sementara Permen KP No. 26 Tahun 2014 (KKP, 2014) menentukan bahwa jarak antara rumpon yang satu dengan rumpon yang lain tidak kurang dari 10 (sepuluh) mil. Oleh karena itu agar pemasangan rumpon mengikuti Permen KP No. 26 Tahun 2014 tersebut.

\section{DAFTAR PUSTAKA}

Bayliff, W.H. 1984. Migrations of yellowfin and skipjack tuna released in the central portion of the eastern Pacific Ocean, as determined by tagging investigations. Internal Rep.I-ATTC, (18): 107 pp.

Davies, N., S. Hoyle, S. Harley, A. Langley, P. Kleiber \& J. Hampton. 2011. Stock assessment of skipjack Tuna in the Western and Central Pacific Ocean. Scientific Committee Seventh Regular Session. 9-17 August 2011, WCPFC, Pohnpey, FSM. 134 pp.

DJPT. 2012. Statistik perikanan tangkap di laut menurut wilayah pengelolaan perikanan (WPP). Direktorat Jendral Perikanan Tangkap, 
Kementerian Kelautan dan Perikanan Republik Indonesia, Jakarta. 468 hal.

Griffiths, S.N., M.T. Zischke, M.L. Tonks, J.G. Pepperell \& S. Tickel. 2012. Innovative and cost effective approaches for surveying specialized recreational longtail tuna fishers in Australian waters. IOTC-2012-WPNT02-16. $2^{\text {nd }}$ Working Party on Neritic Tuna, 19-21 November, PinangMalaysia. $36 \mathrm{pp}$.

Holey, S., P. Kleiber, N. Davies, A. Langley \& J. Hampton. 2011. Stock assessment of bigeye tuna in the western and Central Pacific Ocean. Scientific Committee Seventh Regular Session. 9-17 August 2011, Pohnpey, FSM. 133 pp.

Itano, D.G., 2000. The reproductive biology of Yellowfin Tuna (Thunnus albacares) in Hawaiian Waters and the Western Tropical Pacific Ocean: Project Summary", 2000. David G. Itano. SOEST 00-01, JIMAR Contribution 00-328. 69 pp.

Kementerian Kelautan dan Perikanan. 2014. Peraturan Menteri Kelautan dan Perikanan Republik Indonesia Nomor 26/Permen-Kp/2014 Tentang Rumpon. 15 hal.

Langley, A., S. Holey \& J. Hampton. 2011. Stock assessment of Yellowfin Tuna in the Western and Central Pacific Ocean. Scientific Committee Seventh Regular Session. 9-17 August 2011, WCPFC, Pohnpey, FSM. 135 pp.

Marsac, F. \& P. Cayre. 1997. Fish telemetri applied to behavior analysis of yellowfin tuna in fish aggregating devices network. Second Conference on Fish Telemetry in Europe, La Rochele, 5-6 April 1977.

Morgan, A.C. 2011. Fish aggregating devices and Tuna: Impacts and Management Options. Ocean Science Division, Pew Environment Group, Washington, DC. Photography: @ Masa Ushioda / SeaPics.com. 18 pp.

Murawski, S.A. 2000. Definition of overfishing from an ecosystem prespective. ICES Journal of Marine Science. 57: 649-228.
Nikaido, H., N. Miyabe \& S. Ueyanagi. 1991. Spawning time and frequency of bigeye tuna, Thunnus obesus. Bull.Nat. Res. Inst. Far Seas Fish., 28: p.47-73.

Nontji, A. 2007. Laut Nusantara. Edisi Revisi, Cetakan ke-5, Jakarta, Jambatan, 365 hal.

Nurhakim, S., V.P.H. Nikijuluw, D. Nugroho \& B.I. Prisantoso. 2007. Status perikanan menurut wilayah pengelolaan perikanan (WPP), Informasi Dasar Pemanfaatan Berkelanjutan. Pusat Riset Perikanan Tangkap, Badan Riset Kelautan dan Perikanan. 47 hal.

Romanov, E.V. 2002. By-catch in the tuna purse-seine fisheries of the Western Indian Ocean. Fish Bull.100: p. 90-105.

Schaefer, K.M. 1988. Time and frequency of spawning of yellowfin tuna at Clipperton Island, and plans for future studies. In Proceedings of Tuna Fishery Research Conference, Far Seas Fishery Research Laboratory. Maguro Giyiroku, Suisancho-Enyo Suisan Kendyusho: p. 118-126.

Sulaiman, A. 2000. Turbulensi Laut Banda (Studi Pendahuluan ARLINDO Microstructure). Direktorat Teknologi Inventarisasi Sumberdaya Alam (TISDA) Badan Pengkajian dan Penerapan Teknologi (BPPT). $135 \mathrm{pp}$.

Tampubolon, P.A.R.P., I. Jatmiko, H. Irawati \& A. Bahtiar. 2014. Reproductive biology Of Skipjack Tuna (Katsuwonus Pelamis) In Eastern Indian Ocean, The 16th Working Party On Tropical Tunas IOTC. 15-19 November 2014. Ramada Bintang Bali Resort, Tuban, Kuta, Bali-Indonesia.13 pp.

Widodo, A.A., R.T. Mahulette, B. Wibowo, F. Satria, S. Triharyuni, A. Setiyawan, A. Samusamu, A. Barata, A. Kamaluddin, I.G. Sedana \& L. Sadiyah, 2012. Kajian status stok sumberdaya ikan dan perikanan pelagis di Laut Banda (WPP NRI 714). Lingkungan Perairan, Sumber Daya dan Opsi Pengelolaan Sumber Daya Tuna. Laporan Akhir Kegiatan Penelitian Tahun 2012. Pusat Penelitian Pengelolaan Perikanan dan Konservasi Sumber Daya Ikan, Balitbang Kelautan dan Perikanan, 
Kementerian Kelautan dan Perikanan. (Un Published). 85 hal.

Zhu, G. P., X.J. Dai, L. M. Song \& L. X. Xu. 2011. Size at Sexual Maturity of Bigeye Tuna Thunnus obesus
(Perciformes: scombridae) in the Tropical Waters: a Comparative Analysis. Turkish Journal of Fisheries and Aquatic Sciences. Vol. 11: p. 149156. 